\title{
CASE REPORT: A RARE CASE OF ACCESSORY NIPPLE (POLYTHELIA) PRESENTING AS PAPILLARY ADENOMA
}

\author{
Shekappa C. Malagimani ${ }^{1}$, Jashvanth C. T², Kasasomasekhar ${ }^{3}$, Ulhas Paga ${ }^{4}$
}

\section{HOW TO CITE THIS ARTICLE:}

Shekappa C. Malagimani, Jashvanth C. T, Kasasomasekhar, Ulhas Paga. "Case Report: A Rare Case of Accessory Nipple (Polythelia) Presenting as Papillary Adenoma". Journal of Evolution of Medical and Dental Sciences 2014; Vol. 3, Issue 08, February 24; Page: 2005-2007, D0I: 10.14260/jemds/2014/2095

ABSTRACT: Nipple adenoma is a relatively rare benign breast neoplasm, and cases of the disease arising from the Accessory breast nipple are a rare entity. We report a case of nipple adenoma arising from accessory nipple. A 24-year-old woman presented with the complaint of pain and bleeding from accessory nipple since 4 months in right breast. Physical examination confirmed a well-defined nipple in the milk line $5 \mathrm{~cm}$ below right nipple. The diagnosis of nipple adenoma was made from an excisional specimen on the basis of characteristic histological findings. Because clinically nipple adenoma may resemble Paget's disease and pathologically can be misinterpreted as tubular carcinoma, the correct identification of nipple adenoma is an important factor in the differential diagnosis for nipple neoplasms.

KEYWORDS: Polythelia; Nipple adenoma.

BACKGROUND: Nipple adenoma is a benign proliferative lesion of the breast that arises from galactophorous duct of the nipple. It was first recognized as a distinctive entity in 1955 by Jones who referred to it as "florid papillomatosis" of the nipple duct 1 . Nipple adenoma, also known as nipple duct adenoma, papillary adenoma, erosive adenomatosis, florid papillomatosis, papillomatosis of the nipple and subareolar duct papillomatosis, is a variant of intraductal papilloma involving the terminal portion of the galactophorous ducts ${ }^{2}$. Clinically, nipple adenoma can be mistaken for Paget's disease and can be interpreted pathologically as a tubular carcinoma. We describe the clinical and pathological finding relating to a rare case of nipple adenoma arising in an accessory nipple.

CASE: A 24-year-old woman presented with the complaint of pain and bleeding from accessory nipple since 4 months in right breast. Bleeding was not associated with menstrual cycle. Pain was continuous at irregular intervals. No features suggestive of inflammatory pathology. On physical examination, well-defined nipple was seen in the milk line $5 \mathrm{~cm}$ below right nipple. There was bleeding on pressing the accessory nipple and the primary nipple was normal. The axillary lymph nodes were not palpable. No neoplastic lesions were detected in the patient's breast.

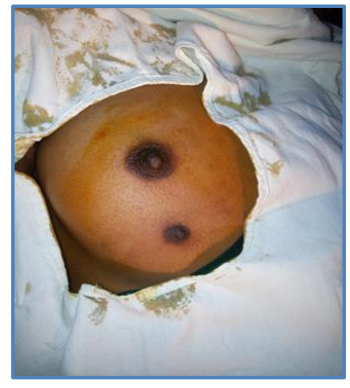

Fig. 1A: Accessory Nipple

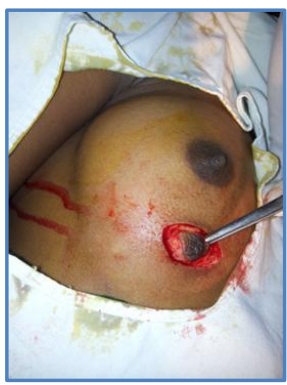

Fig. 1B: Local Excision 


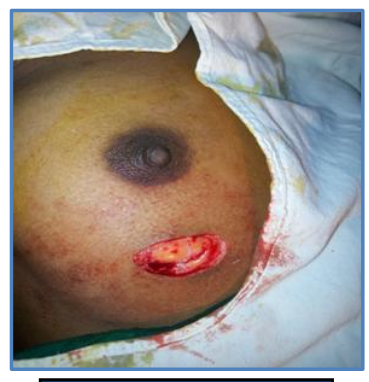

Fig. 1C: Base

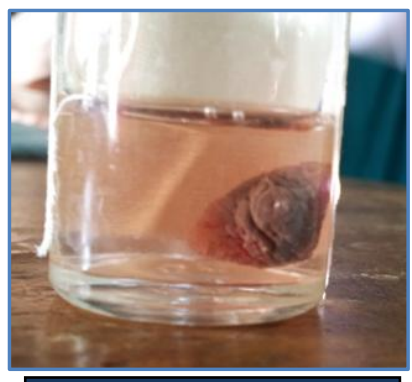

Fig. 1D: Specimen

Complete local excision of accessory nipple was performed under local anesthesia. Histologically, the specimen was diagnosed as nipple adenoma arising from the accessory nipple. Pathological findings were a clearly defined proliferation of ductules around dilated lactiferous ducts. Some ductules showed micropapillary epithelial hyperplasia. They were proliferating two cell layered glands sprouting from and compressing the ducts resembled adenosis (Figure 2,a). The tumor exhibited central dilated lactiferous ducts and a pseudoinvasive tubular pattern with dense stroma in the peripheral regions (Figure 2,b). The glandular cells had fairly regular, uniform, round to oval nuclei. There was no hyperchromasia, pleomorphism or mitotic activity. Inflammatory cell infiltration was mild around the ductules, and fibrosis was considerable.

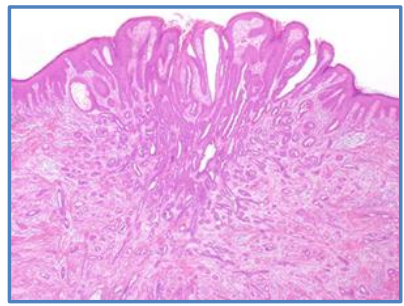

Fig. 2A: Complex proliferation of ductless around dilated lactiferous ducts

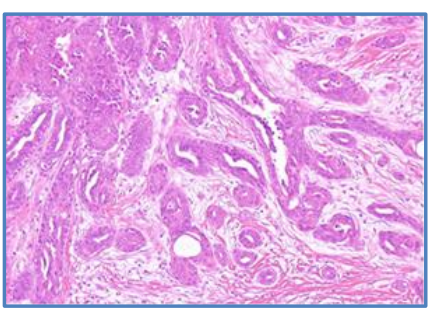

Fig. 2B: Ductules with internal micropapillary proliferations

DISCUSSION: Accessory nipple generally develops along the embryonic mammary ridge that extends from the axilla to the groin. Accessory nipple has a relatively common occurrence with an incidence of 1 in 18 males and 1 in approximately 50 female humans.

A number of different neoplasms, both benign and malignant, have been found in axillary nipple. Nipple adenoma is one of the rare benign types which develop within or in the superficial portion of the nipple. On physical examination, the most common findings are an eroded, ulcerated, crusted nipple and a palpable nodule ${ }^{3}$; and nipple adenoma can be mistaken clinically for Paget's disease ${ }^{4}$. In the present case, the papilloma arose from the accessory nipple

Microscopically, nipple adenoma is composed of a proliferation of small tubular structures displaying double layers 5 . Nipple adenoma is a complex benign mammary proliferation that has a variety of histologic appearances. Rosen and Caicco classified nipple adenoma into four morphological patterns:

1) sclerosing papillomatosis; 2) papillomatosis; 3) adenosis; and 4) mixtures of these proliferative patterns [5].

In our case, the tubular structure formed a complex branching pattern with some micropapillary epithelial hyperplasia and was classified as having a mixed pattern. The 
galactophorous ducts had a squamous cell metaplasia close to the skin. This feature is also a valuable criterion for the identification of nipple adenoma1. An adenosis and pseudo infiltrative pattern were also prominent in the present case, and resembled invasive tubular carcinoma or adenosquamous carcinoma. However, demonstration of the two layer structure consisting of a myoepithelial layer surrounding the epithelial tubules, and the relative uniformity and coherence of the cells, indicated the benign nature of the tumor'2.

Standard treatment for nipple adenoma is local excision ${ }^{3}$. Although nipple adenoma has basically been suggested as being a benign tumor, the relationship between nipple adenoma and carcinoma has not been elucidated entirely ${ }^{6}$. This is necessary to confirm the requirement for complete resection of the tumor and pathological retrieval. Recognition of this disease by both the clinician and the pathologist, and close communication between them is important in avoiding misdiagnosis of malignancy and unnecessarily extensive surgery.

CONCLUSIONS: A case of nipple adenoma arising from accessory nipple was reported here. The correct identification of nipple adenoma is an important factor in the differential diagnosis of nipple neoplasms. Recognition of this rare benign condition is important in preventing misdiagnosis of malignancy.

\section{REFERENCES:}

1. Jones DB. Florid papillomatosis of the nipple ducts. Cancer 1955, 8:315-319.

2. Tayor HB, Robertson AG. Adenomas of the nipple. Cancer 1965, 18:995-1002.

3. Perzin KH, Lattes R. Papillary adenoma of the nipple (florid papillomatosis, adenoma, adenomatosis). A clinicopathologic study. Cancer 1972, 29:996-1009.

4. Healy CE, Dijkstra B, Walsh M, Hill AD, Murphy J. Nipple adenoma: a differential diagnosis for Paget's disease. Breast J 2003, 9:325-326.

5. Tavassoli FA, Devilee P. World health organization classification of tumours, Pathology and genetics of tumours of the breast and female genital organs. Lyon: IARC Press; 2003:104-105.

6. Rosen PP, Caicco JA. Florid papillomatosis of the nipple. A study of 51 patients, including nine with mammary carcinoma. Am J Surg Pathol 1986, 10:87-101.

\section{AUTHORS:}

1. Shekappa C. Malagimani

2. Jashvanth C. T.

3. Kasasomasekhar

4. Ulhas Paga

\section{PARTICULARS OF CONTRIBUTORS:}

1. Associate Professor, Department of Surgery, VIMS, Bellary.

2. Post Graduate Student, Department of Surgery, VIMS, Bellary.

3. Professor, Department of Surgery, VIMS, Bellary.

4. Post Graduate Student, Department of Surgery, VIMS, Bellary.

\section{NAME ADDRESS EMAIL ID OF THE} CORRESPONDING AUTHOR:

Dr. Shekappa C. M, B/24, Staff Quarters, VIMS (OPD) Cantonment, Bellary.

E-mail: doc_shekar@yahoo.com

Date of Submission: 29/01/2014.

Date of Peer Review: 30/01/2014.

Date of Acceptance: 08/02/2014.

Date of Publishing: 21/02/2014. 